\title{
The role of Eph receptors in lens function and disease
}

\author{
SON Alexander I., PARK Jeong Eun \& ZHOU RenPing ${ }^{*}$ \\ Department of Chemical Biology, Ernest Mario School of Pharmacy, Rutgers, The State University of New Jersey, Piscataway, \\ NJ 08854, USA
}

Received April 16, 2012; accepted April 27, 2012

\begin{abstract}
Cataract is the single largest contributor to blindness in the world, with the disease having a strong genetic component. In recent years the Eph family of receptor tyrosine kinases has been identified as a key regulator in lens clarity. In this review we discuss the roles of the Eph receptors in lens biology and cataract development.
\end{abstract}

cataract, lens, EphA2, ephrin-A5

Citation: Son A I, Park J E, Zhou R. The role of Eph receptors in lens function and disease. Sci China Life Sci, 2012, 55: 434-443, doi: 10.1007/s11427012-4318-7

Visual impairments, a disability characterized by blindness and low vision, continue to be a major global health problem in the 21 st century, affecting over 161 million people worldwide [1,2]. Of this, the single largest contributor of global blindness is cataract, or the opacification of the lens, accounting for nearly $50 \%$ of all cases of visual deficits [1-3]. While the condition is normally associated with aging and environmental factors, advances in human disease gene mapping have revealed a strong genetic component. To date, mutations in more than 35 loci within the human genome have been identified as the cause of cataracts, with the recognized genes being associated with lens development and maintenance $[4,5]$.

One recent addition to the list of molecules found to be indispensible to lens integrity and clarity is the Eph family of receptor tyrosine kinases and their ligands the ephrins. This group of signaling factors has now been shown as a key regulator of mammalian lens development and function. Here, we discuss the role of the Eph family in the formation and maintenance of the lens.

*Corresponding author (email: rzhou@ @ri.rutgers.edu)

\section{Lens development and organization}

\subsection{Development and morphology}

The lens is a transparent ellipsoid tissue situated anterior to the retina. The bulk of the lens consists of organelle-less lens fiber cells; the oldest cells, formed during embryonic development (known as primary fiber cells), comprise the core of the tissue while the youngest and most newly formed cells (known as secondary fiber cells) are found more distally away from the center (Figure 1). The anterior face of the tissue comprises of a single layer of epithelium that consistently divides and differentiates into mature fiber cells. The entirety of the structure is encompassed within an elastic capsule.

The distinct anterior-posterior polarity of the lens is established during the initial developmental stages of the tissue and has been extensively reviewed [6,7]. The murine eye begins to form as early as embryonic day 8.5 (E8.5) with the protrusion of the optic vesicle from the developing forebrain near the head ectoderm. By E9.5, the overlying optic vesicle thickens to form the lens placode. At E10.5 these two areas invaginate, the lens placode forming the 


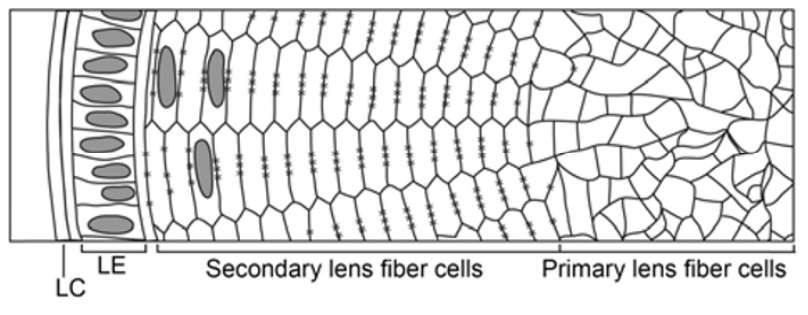

Figure 1 A cross-sectional view of the mature lens. The core of the lens consists of irregularly-shaped primary lens fiber cells formed during the early stages of lens development. After the initial development of primary fiber cells, secondary lens fiber cells form continuously from this core and are arranged in regular hexagonal structures. The anterior face of the lens contains a monolayer of lens epithelial cells (LE) that continually divide and differentiate into secondary lens fiber cells. The entire structure is encapsulated by a lens capsule (LC). * denotes gap junction complexes along the long edges of secondary fiber cells.

lens pit and the optic vesicle producing the optic cup. The lens pit deepens at E11.5 to form the lens vesicle, and by E12.5 the vesicle has completely closed and pinched off from the surface ectoderm. At E13.5, lens cells at the posterior portion of the lens extend outwards towards the anterior layer of cells and fill the lumen, with the single stratum of cells in the anterior portion becoming the lens epithelium and the elongated cells forming the primary lens fiber cells.

Growth of the lens after initial formation continues through embryonic development and into the postnatal stages [6]. Lens epithelial cells anterior to the lens equator, a region known as the germinative zone, continue to divide, replacing cells undergoing differentiation. Meanwhile, the epithelial cells near the equator, an area known as the transitional zone, elongate and differentiate into secondary lens fiber cells, continually adding onto the pre-existing lens structure and comprising the major part of the lens.

While the primary fiber cells are irregularly-shaped [8], the secondary fiber cells are highly organized elongated structures arranged in meridional rows [9] (Figure 1). In cross-section, the secondary fiber cells are arranged into flattened hexagons with two parallel long edges connected by four shorter edges. Enlargement of the lens involves the overlaying of mature fiber cells with additional layers of newly formed differentiated cells, or growth shells. Each supplementary shell adds to the diameter of the lens, a combination of the addition of more secondary fiber cells and the widening of fiber cells [9].

\subsection{Transparency}

As the primary role of the lens is to provide proper light refraction to the retina, the organ must possess several inherent characteristics, including stability, clarity, and the proper refractive index, to function appropriately. This is made possible in part through key features of the cytoplas- mic content of lens fiber cells. One particularly unique aspect of lens fiber cells is their absence of organelles [10]. Occurring during the later aspects of the differentiation process, fiber cells experience a gradual degradation of nuclei and organelles over a span of several days in what has been described as an "attenuated apoptosis" [10,11]. This event is crucial for maintaining lens transparency as the absence of internal cellular structures allows light to travel unimpeded through the structure to the retina [12].

In addition to the loss of organelles, fiber cells achieve their appropriate refractive properties through regulation of their protein content. The bulk of the lens consists of soluble proteins known as the crystallins, a family comprising of $\alpha-, \beta-$, and $\gamma$-crystallins $[13,14]$. Crystallins represent $90 \%$ of the protein in the lens and provide the proper refractive medium for light passage within the lens. In addition to structural functions, $\alpha$-crystallin is capable of chaperone activity, preventing aggregation of proteins denatured by various stressors [15-17]. This chaperone activity is particularly important in the prevention of protein aggregation that may otherwise lead to insolubility and result in cataract formation. $\alpha$-crystallins are expressed in both the lens epithelium and fiber cells, while $\beta$ - and $\gamma$ - crystallins are exclusively in differentiated lens fiber cells and are indicators of lens cell differentiation [14,18].

\subsection{Circulation and intercellular interactions}

\subsubsection{Gap junctions and aquaporins}

The early embryonic lens is supplied with nutrients through a blood vessel network known as the hyaloid vasculature. However, this complex regresses in later stages of ocular development, leaving the mature lens in an avascular environment $[19,20]$. To preserve homeostasis, the lens depends on both an internal circulation system and its unique cytoarchitecture to maintain proper water and nutrient content. This circulation is regulated by two major protein families: gap junctions and aquaporin channels.

Gap junctions are specialized intercellular channels formed by two adjacent cells that allow for the passage of small molecules. The structures consist of connexin molecules, with six molecules of either the same (homomeric) or different (heteromeric) connexins forming a hemichannel known as a connexon, which in turn interacts with another hemichannel from an adjacent cell [21].

The lens consists of three main connexin molecules: connexin-43 (Cx-43) is expressed in low levels exclusively in the lens epithelium [22], connexin-46 (Cx-46) is observed solely in the differentiated lens fiber cells [23-25], and connexin-50 (Cx-50) is observed in both the lens epithelium and fiber cell layers. Both $\mathrm{Cx}-46$ and $\mathrm{Cx}-50$ are capable of interacting to form heteromeric hemichannels, but $\mathrm{Cx}-43$ has not been found to interact with either $\mathrm{Cx}-46$ or $\mathrm{Cx}-50$ [21]. Connexins in the lens also interact with the 
scaffolding protein zona occludens-1 (ZO-1), and this interaction has been found to play a role in gap junction assembly [25-28].

Gap junction complexes are the major driver of communication, circulation, and exchange of resources within the lens. Studies using knock-out mouse models of $\mathrm{Cx}-46$ $\left(\mathrm{Cx}-46^{-1-}\right)$ and $\mathrm{Cx}-50\left(\mathrm{Cx}-50^{-1-}\right)$ have found reductions in fiber cell conductivity $[29,30]$. In addition, Cx-50 plays a critical role in lens growth and development, as $\mathrm{Cx}-50^{-1-}$ lenses experience growth deficits in lens fiber maturation [31,32].

Lens circulation is also mediated through the passive diffusion of water in the lens. This process is regulated by the aquaporin family of molecules, transmembrane molecules that form tetramers and are permeable to water [21]. The lens consists of two main aquaporins: the lens epithelium consists of predominantly Aquaporin 1 (AQP1) [33,34] while the lens fiber cells express Aquaporin 0 (AQP0), formerly known as major intrinsic protein (MIP) [35,36].

\subsubsection{Adherens junction: the cadherins}

The unique hexagonal shape of lens fiber cells requires the regulation of intercellular interactions. This role is mediated in part by the cadherins, a major family of intercellular adhesion molecules involved with the dynamic regulation of tissue morphogenesis [37]. The most extensively studied of these molecules are the classical cadherins, transmembrane homophilic adhesion molecules whose interactions are regulated by calcium $[37,38]$.

The classical cadherins affect cellular connections and shape through interactions with the actin cytoskeleton [39]. This interaction is regulated in the C-terminus of the cadherin molecule through a complex collectively known as the adherens junction. The proteins of this complex include several molecules of the catenin family, including $\beta$-catenin, p120-catenin, and $\alpha$-catenin. $\beta$ - and p120-catenin are armadillo repeat proteins that interact directly with the cadherin molecules; p120-catenin binds to cadherin molecules at the juxtamembrane domain, while $\beta$-catenin interacts with the cytoplasmic domain in competition with another catenin molecule, $\gamma$-catenin (alternatively known as plakoglobin), which is often associated with desmosomes [40-43]. The binding between the catenin and cadherin molecules are mediated by the phosphorylation of tyrosine residues [44]. Phosphorylation of $\beta$-catenin results in disruptions with their interactions of cadherins, while phosphorylation of $\gamma$-catenin can either enhance or reduce affinity to cadherin complex depending on the affected residue [45]. The adherens junction complex interacts with the actin cytoskeleton and is dependent on $\alpha$-catenin [39].

The lens contains two of the classical cadherins: E-cadherin is expressed exclusively in the lens epithelial layer, while $\mathrm{N}$-cadherin is present in both the epithelial and fiber cell layers [46-48]. These molecules are essential in lens development and maintenance, as conditional deletions of either cadherin result in severe lens deficits [48]. Both Eand $\mathrm{N}$-cadherin are necessary for lens vesicle separation [48]. In addition, $\mathrm{N}$-cadherin plays important roles in lens fiber cell elongation and morphogenesis [47-49].

\subsection{The Eph family and the lens}

Lens clarity depends on the proper regulation of several critical features including structural integrity, cellular adhesion and packing, protein stability, cell-cell communication, and circulation. Mutations in the Eph receptor EPHA2 have been recently shown to cause cataracts in humans [50-55]. The loss of functions of Eph receptors may affect one or several of these processes resulting in cataractogenesis. Continuing investigations on the roles of the Eph receptor family in the lens will reveal how these factors are directly or indirectly affected.

\section{The Ephs and ephrins}

Receptor tyrosine kinases (RTKs) are crucial factors in regulating wide arrays of basic cellular processes [56,57]. The largest subclass of this group is the Eph family, named after the erythropoietin-producing hepatocellular carcinoma cell lines in which the first Eph receptor was isolated [58]. The Ephs had originally been associated with neuronal development in the guidance of neuronal processes to their respective targets through repulsive effects [59,60]. Since their initial discovery, the Eph family has been found to be expressed in a wide assortment of tissues and is implicated in several key biological functions including axonal guidance, neural plasticity, angiogenesis, tissue patterning, cell proliferation, differentiation, and pathogenic processes such as cancer [59].

\subsection{Families}

Eph receptors are divided into the EphA and EphB subgroups based on both their extracellular surface sequence homology and their preference for interacting with either the ephrin-A or ephrin-B ligands, respectively $[59,60]$. Interactions between the receptors and ligands are promiscuous within their respective classes; EphA receptors have the capacity to interact with ephrin-A ligands, while EphB receptors have the ability to bind to ephrin-B ligands. Binding between receptor-ligand classes are also possible and may also play important biological roles [61-64]. To date, 14 Eph receptors (EphA1-EphA8, EphA10; EphB1-EphB4, EphB6) and 8 ephrin ligands (ephrin-A1-ephrin-A5, ephrinB1-ephrin-B3) have been identified in mammals [60].

\subsection{Structure and domains}

The protein structure is highly conserved between both the 
EphA and EphB subgroups [59,60,65]. The extracellular portion of the receptors contains an ephrin ligand-binding domain at the $\mathrm{N}$-terminus, followed by a cystein-rich region epidermal growth factor (EGF) repeat motif and two fibronectin type-III repeats. The intercellular portion contains the signaling components which include a juxtamembrane region, a tyrosine kinase domain, a sterile alpha motif (SAM), and a PDZ binding domain at the end of the C-terminus.

Recent studies on Eph receptor mutations in human cataracts have found the SAM domain to be of particular importance in maintaining lens clarity $[50,53,55]$. The SAM domain is among the most ubiquitous protein interaction domains and is involved with the regulation of several biological processes, amongst which include protein clustering, kinase regulation, and transcriptional and translational control [66]. However, the role of the SAM domain in regards to Eph receptor function remains poorly understood. Structural studies on the EphA4 and EphB2 SAM domains have yielded the potential for Eph receptor clustering; the EphA4 SAM domain is capable of forming dimers while the EphB2 SAM domain has the capacity of forming oligomers, though the biological relevance of these interactions remains unclear [67-69]. Deletion of the EphA4 SAM domain does not affect the activity of the receptor during the development of thalamocortical axons and does not affect kinase activity or clustering and ligand activation [70,71]. Interestingly, Phe-for-Tyr mutations at position 928 within the EphA4 SAM domain had a pronounced effect in Xenopus development by enhancing ectopic induction of posterior protrusions, indicating that the EphA4 SAM domain may play some role in inhibiting EphA4 activity in vivo [72].

Ephrin ligands are physically bound to the cell surface, with the major distinction between the two subclasses being in the mechanism of attachment; ephrin-A ligands interact with the surface through a glycosylphosphatidylinositol (GPI) anchor, while ephrin-B ligands have a transmembrane domain. This surface localization of the ephrin ligands plays a key role in their signaling attributes, particularly in the ability for the ligand to cluster and oligomerize to induce signaling [59,73-75]. The GPI-anchored ephrin-As have the capacity of being cleaved [76]. More recent studies have also found that soluble ephrin-As, both in monomeric and oligomeric forms, may have biological roles and can also affect signaling [77,78].

\subsection{Signaling and activation}

Eph receptor activation is induced by interactions with their respective ephrin ligands. Because both the receptors and ligands are typically membrane-bound, interactions between Eph-ephrin pairs require direct intercellular contact. The Eph-ephrin system is particularly unique in that signaling can occur in a bidirectional manner, in which interactions between the Eph receptor and ephrin ligand can induce ac- tivation in the receptor-expressing cell (forward signaling), ligand-expressing cell (reverse signaling), or both cells (bidirectional signaling) [59]. Eph receptor activation results in activation of the kinase domain and both the Eph receptor and ephrin ligand may be associated with various effector proteins which may or may not be associated with kinase activity [79]. These effectors include the Src kinase family and the Ras and Rho GTPases, which in turn can cause changes in actin cytoskeletal dynamics $[79,80]$.

\section{The roles of Ephs and ephrins in the lens}

\subsection{EPHA2 and cataracts in human populations}

Recent genetic studies in congenital and age-related cataracts have identified the Eph family to be a key regulator of lens development. The human chromosome region 1p36 has been previously identified as a locus for autosomal dominant posterior polar cataracts [81-84]. Analysis of affected genes within this region has identified mutations in the Eph receptor EPHA2 to be a risk factor of congenital and age-related cataract patients (Figure 2).

Thus far, six studies have identified human populations with both congenital and age-related cataracts as a result of mutations within EPHA2 [50-55]. Of the identified human mutations, five variants result in autosomal dominantinherited cataracts $[53,55]$ while one mutation leads to recessive congenital cataracts [51]. The human EPHA2 cataract mutations have been localized to the intracellular compartment of the receptor.

Four of the known mutations identified from independent families thus far have been located within the SAM domain. Two are point mutations that result in posterior polar cataracts: Shiels et al. identified a transversion mutation (c.2842G>T) which changes the translation of glycine into tryptophan at codon 948 (G948W) [55], while Zhang et al. identified a missense mutation (c.2819C $>$ T) which replaces a threonine at codon 940 with an isoleucine residue (T940I) [53]. Additionally, Zhang et al. identified two more cataract mutations, including a splicing mutation (c.2826-9G $>$ A) [53] which creates a splice acceptor site at intron 16 resulting in a 7 base pair intron sequence insertion and resulting in posterior polar cataracts, and a frameshift mutation (c.2915_ 2916delTG) [53] that leads to total cataracts. These latter two mutations result in novel C-terminal sequences of EPHA2; c.2826-9G >A forms a C-terminal polypeptide of 71 amino acid residues, while c.2915_2916delTG forms a polypeptide of 39 amino acids [53]. Interestingly, these latter two described mutations share the same last 39 amino acid residues. To date, all described SAM domain cataract mutations are autosomal dominant $[53,55]$ suggesting inactivating interactions with the wild-type EPHA2 receptor.

The kinase domain of EPHA2 also plays important roles in lens regulation, as mutations within this region have been found to cause cataracts in human populations [50,51]. Jun et al. [50] 


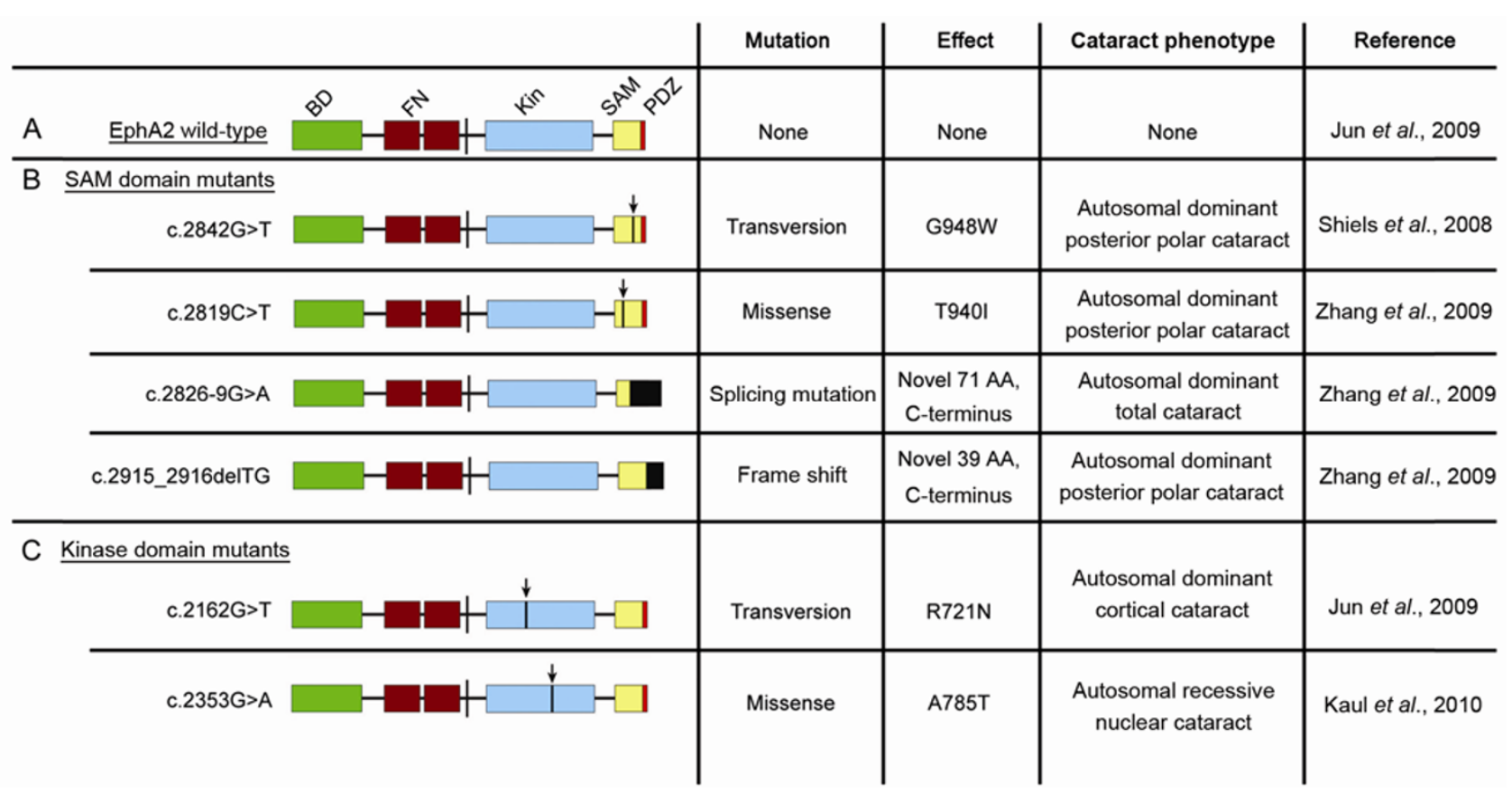

Figure 2 Human EphA2 cataract mutations. A, Structure of wild-type EphA2. BD, ephrin ligand binding domain; FN, fibronectin repeats; Kin, kinase domain; SAM, sterile alpha motif; PDZ, PDZ domain. B, EphA2 SAM Domain cataract mutants. C, EphA2 kinase domain cataract mutants. Arrows denote relative location of point mutations in indicated mutations. Black boxes denote novel amino acid changes.

identified a transversion mutation (c. $2162 \mathrm{G}>\mathrm{T})$ resulting in a change of codon 721 from an arginine to a glutamine residue $(\mathrm{R} 721 \mathrm{~N})$ and leading to cortical cataract with autosomal dominant inheritance. Kaul et al. [51] has also described a missense mutation (c.2353 G>A) within the kinase domain resulting in the substitution of alanine for a threonine at codon 785 (A785T) and causing the formation of a nuclear cataract. This is the only EPHA2 cataract mutation identified so far to be of autosomal recessive inheritance.

\section{2 $\operatorname{EphA2}^{-/-}$mouse models and characterization}

Knock-out mouse models have also identified members of the Eph family as important regulators of lens development and function. Age-related cortical cataracts in EphA2 $2^{-/-}$ mutant mouse models have been reported by Jun et al. In this study, the EphA $2^{-/-}$mice were generated using a secretory gene trapping technique in which a secretory trapping vector was inserted at exon 5 [85]. In these mice, the extracellular domain of EphA2 was fused to a neomycine-resistance- and- $\beta$-galactosidase reporter cassette that remained confined within secretory vesicles $[50,85]$. Additionally, EphA $2^{-/-}$mice developed using retroviral insertion into the first codon of EphA2 were also analyzed [50]. In both mouse backgrounds, lens deficiencies were observed as early as one month after birth with the formation of subcapsular vacuoles in the anterior cortex, followed by lens opacity and rupture by 8 months of age. Incidence of cataracts in the EphA $2^{-/-}$mutants were observed in over $80 \%$ of the mice by 12 months of age while no cataract formation was observed in EphA2 $2^{+/+}$or EphA2 $2^{+/-}$animals. The group had also reported an upregulation of HSP25 in EphA2 $2^{-/-}$ lenses, which is related to $\alpha \mathrm{B}$-crystallin and is a marker for oxidative stress in lenses undergoing cataract formation [50,86-88].

Shi et al. [89] had also found lens deformations in EphA2 $2^{-1-}$ mice developed using an in-frame translational stop codon at exon 5 under a $\mathrm{S} 129$ and $\mathrm{C} 57 \mathrm{Bl} / 6$ mixed background; however, these mice did not develop cataracts. In this study, the absence of EphA2 resulted in abnormalities in lens shape and composition, resulting inaccurate light refraction. Lens suture deficits were observed in these mice, indicating possible problems in lens cell migration [90,91]. In addition, these EphA $2^{-/-}$mice also had persistent epithelial lesions. The disparity of lens phenotypes in this EphA2 mutant model versus those described in by Jun et al. remains unclear, though the differences in mouse backgrounds may play a role.

\subsection{Cataract formation in ephrin- $\mathrm{A5}^{-/-}$mice}

The Eph receptor ligand ephrin-A5 has also been identified to play a key role in lens development, as mice deficient for ephrin-A5 have been found to develop cataracts [92,93]. Cooper et al. had first reported the cataracts in ephrin-A $5^{-/-}$ mice, with the mutants having significant lens fiber cell deficiencies [92]. In cross-section, lens fiber cells in the ephrin-A $5^{-1-}$ mice lack the standard hexagonal shape and are instead more rounded. Lens deficits were observed as early as postnatal day 6 with the formation of vacuoles in 
the lens bow region, with complete lens rupture observed by 2 months of age. EphA2 was shown to be the putative receptor for ephrin-A5 in the lens, as a similar localization of both the receptor and ligand are observed within the lens fiber cell regions. Additionally, EphA2 phosphorylation is reduced in the ephrin- $\mathrm{A} 5^{-/}$lens in comparison to wild-type controls. Gap junction alignment within these lenses was disrupted in the mutants compared to wild-types, but the membrane localization and presence of large gap junction complexes in the subcortical zone implies that this is a result of structural changes within the lens and not a direct regulation of these proteins by ephrin-A5 (data unpublished). The absence of ephrin-A5 results in the severe disorganization of the adherens junctions.

A later study by Cheng and Gong confirmed cataract development in the ephrin-A $5^{-/}$mice [93]. The group found that ephrin-A5 plays a critical role in maintaining anterior epithelial cells, as the ligand is expressed in the lens epithelium and that the loss of ephrin-A5 resulted in aberrant epithelial cells mislocalizing in the lens fiber cell layer. The deficits in these mutant lenses were also observed to be related to misregulation of adherens junction molecules.

While both Cooper et al. and Cheng and Gong have identified lens deficits in ephrin- $\mathrm{A} 5^{-/}$mice and found that the adherens junction complex is affected, there have been discrepancies in regards to the underlying mechanisms of cataractogenesis. Cooper et al. identified major disruptions in lens fiber cell organization and found ephrin-A5 expression within the fiber layers of the lens. In contrast, Cheng and Gong reported that significant impairments were in the arrangement of lens epithelial cells with more limited fiber cell disruptions in the ephrin-A $5^{-/-}$lens. In this latter study, expression of ephrin-A5 was observed in the lens epithelium but not in the fiber cells. Possibilities for this discrepancy may be due to the reagents used or differences in mouse genetic backgrounds; mice used in the study by Cheng and Gong were mostly a C57B1/6 background strain while Cooper et al. used animals of a mixed background that includes S129. The S129 strain has previously been identified to have a mutation in the gene for the lens-specific intermediate filament protein CP49 [94,95]. Whether the cataracts observed within the mixed background mice are influenced by the CP49 mutation remains to be determined.

\subsection{Eph receptor and ephrin ligand expression in the lens}

Thus far, only EphA2 and ephrin-A5 have been found to have major roles in lens development and function. Expression of EphA2 in the lens has been reported to be within the fiber layer, most notably within the subcortical region, with some expression in epithelial cell layers [50,89,92,93]. Ephrin-A5 has similar localizations, with expression observed in the subcortical fiber layer [92] as well as within the lens epithelial layer [93]. In the mature lens, both EphA2 and ephrin-A5 expression has been observed in the short edges of lens fiber cells when lenses are oriented in cross-section [89,92]. Additionally, we and others have found that ephrin-A5 and EphA2 are expressed in the presumptive lens at early embryonic stages and continue to be expressed in both the lens epithelium and fiber cell regions into adulthood (data unpublished) (Figure 3) [96].

Other Eph receptors and ephrin ligands have also been identified within the lens. Ephrin-A1 protein expression has been seen in lens fiber cell layers around the subcortical region as well as in the epithelium [50]. Our group had also performed RT-PCR analysis on the lens and has observed expression of several other Eph receptors and ephrin ligands (data unpublished). However, to date, no other cataract phenotype has been reported with inactivation of any other Eph family molecule other than EphA2 and ephrin-A5. Using Eph receptor- and ephrin ligand-binding techniques, we have also observed extensive expression of Eph family molecules throughout lens development as early as E12 (data unpublished), indicating a possible role during early lens development.

\section{Mechanisms underlying cataract develop- ment caused by Eph family mutations}

\subsection{Contributions of the EPHA2 SAM domain}

The human EPHA2 cataract studies have yielded a surprising finding: that the SAM domain plays a valuable role in
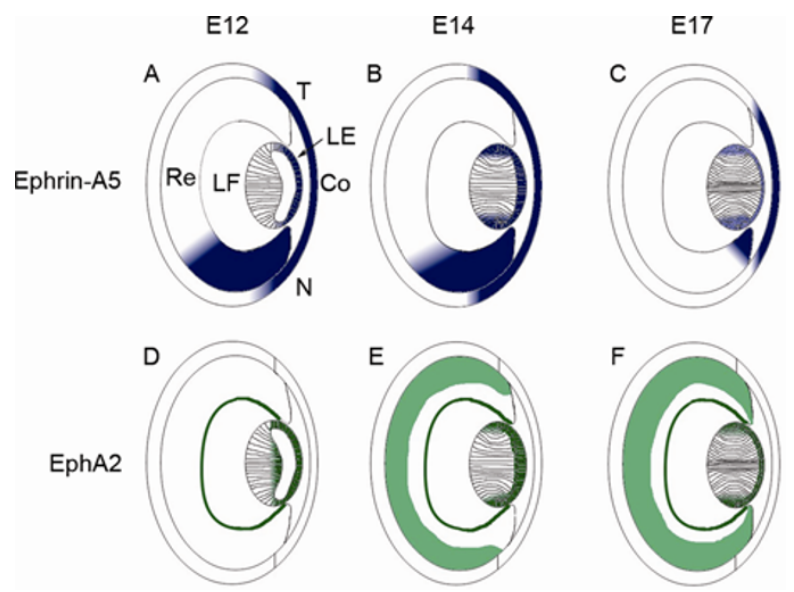

Figure 3 Expression of ephrin-A5 and EphA2 during ocular development A-C, Ephrin-A5 expression at E12 (A), E14 (B), and E17 (C) is observed in the lens epithelium, lens fiber layer around the bow region, cornea, and the retina. Expression within the retinal region is graded with higher expression towards the nasal retina. Ephrin-A5 levels within the developing eye are reduced at later stages. D-F, EphA2 expression at E12 (D), E14 $(\mathrm{E})$, and E17 (F) is observed in the lens epithelium, fiber cell layers, and parts of the retina during ocular development (data unpublished). Within the lens, EphA2 is observed in several of the same regions as ephrin-A5 has been found to be expressed (data unpublished). LE, lens epithelium; LF, lens fiber cells layer; Re, retina; Co, cornea; $\mathrm{N}$, nasal retina; $\mathrm{T}$, temporal retina. 
maintaining EphA2 function in the lens. Four mutations out of a total of six known cataract mutations in EPHA2 are within the SAM domain. Significantly, all of the identified SAM domain mutations have been found to be autosomal dominant $[53,55]$.

The role of the EPHA2 SAM domain in lens regulation remains to be elucidated. The frameshift mutation c.2915_ 2916delTG and splicing mutation c.2826-9G $>$ A both show enhanced protein-protein interactions with low molecular weight protein-tyrosine phosphatase (LMW-PTP), which normally associates with the C-terminus of EPHA2 and inhibits its phosphorylation [53,97-99]. The amplified interaction is more pronounced in the c.2826-9G>A mutant [53]. This enhancement may be attributed to the novel polypeptide formation in the $\mathrm{C}$-terminus as a result of the mutations, but must be further elucidated as to the direct cause. Further analysis of the EPHA2 SAM domain mutations by our group has found that these mutations affect the stability of EPHA2 through ubiquitin-mediated proteasomal degradation and influence protein solubility. Additionally, these cataract mutations inhibit normal EPHA2 function in promoting cell migration activity [90].

While the human EPHA2 SAM domain mutations result in an autosomal dominant phenotype, the EphA2 mutant mouse models develop cataracts in an autosomal recessive manner, as EphA $2^{-/-}$mice develop cataracts while EphA2 ${ }^{+-}$ display normal lenses [50]. One possibility for this difference may be that the EphA2 SAM domain mutations has a dominant-negative effect on the normal EphA2; mutations within the EphA2 SAM domain could potentially interrupt proper oligomerization, impeding proper signaling. Another possibility is that interactions between wild-type EphA2 and mutated EphA2 SAM domain proteins result in inhibition of downstream signaling targets. Work by our group has found that the EPHA2 SAM domain mutations impair Akt signaling upon binding with ephrin-A5 [90]. The replacement of wild-type EphA2 with these EphA2 SAM domain mutants in mouse studies will prove insightful to further elucidate this mechanism.

\subsection{Roles of EPHA2 kinase activity}

Examinations on the function of EPHA2 in human cataracts have also revealed the kinase domain to play a critical role in regulating lens activity. Jun et al. had identified an $\mathrm{R} 732 \mathrm{~N}$ mutation within the kinase domain as a risk allele for cataracts in human populations. Analysis of the EPHA2 kinase domain crystal structure [100] identified Arg721 to be important in forming a salt bridge with Asp872. Biochemical experiments found the R721N mutation (R721NEPHA2) to result in higher basal activation of the EPHA2 receptor compared to wild-type EPHA2, which leads to enhanced basal activity of ERK1/2. Furthermore, HEK293 cells expressing R721N-EPHA2 in the presence of the
ephrin-A1 ligand showed an inhibition to growth, while mouse embryonic fibroblasts (MEFs) expressing R721NEPHA2 showed intracellular retention of the protein [50]. The relevance of these results to lens biology in vivo is still unclear.

The kinase domain missense mutation c. $2353 \mathrm{G}>\mathrm{A}$ has also been identified as a risk allele for cataracts in resulting in an autosomal recessive congenital cataracts [51]. However, effects of this mutation on EPHA2 kinase activity remain to be elucidated.

\subsection{Regulation of the adherens junction by the Eph family in the postnatal lens}

Mouse studies focusing on both ephrin-A5 and EphA2 in the lens have identified the adherens junction as a potential downstream target $[92,93]$. The relationship between the Eph family and the cadherins has been previously documented [99,101-105]. Within the context of the lens, protein localization of the adherens junction molecules are disrupted in both the ephrin-A $5^{-/-}$and EphA $2^{-/}$lenses [92,93]. Cooper et al. observed that $\mathrm{N}$-cadherin becomes internalized in the lens fiber cells as early as P6, at which point lens fiber cell architecture is already disordered in the ephrin-A $5^{-/-}$lens. Interestingly, $\beta$-catenin expression, a regulator of cadherin binding with the actin cytoskeleton, was observed on the membranes of the lens fiber cells, implying that ephrin-A5 may play a role in the regulation of $\mathrm{N}$-cadherin- $\beta$-catenin interaction. Furthermore, in vitro experiments have found that ephrin-A5 and EphA2 are capable of enhancing the interaction between $\mathrm{N}$-cadherin and $\beta$-catenin, and EphA2 has been observed to interact directly with $\beta$-catenin [92]. Cheng and Gong have also reported disruptions of the adherens junction complex, most notably in the lens epithelium. Ephrin-A $5^{-/-}$lens epithelium were found to have abnormal E-cadherin and $\beta$-catenin localization. More limited disruption of $\mathrm{N}$-cadherin was observed in the ephrin- $\mathrm{A} 5^{-/}$lens in this genetic background. In addition, the group observed disruptions in EphA $2^{-/-}$lens fiber cells, with disruptions in $\mathrm{N}$-cadherin expression in fiber cell layers.

Together, the evidence from both studies suggests that the Eph family has a direct role in regulating the adherens junction in the developing lens. More specifically, the Eph family appears to play key roles in cadherin regulation through $\beta$-catenin. Along with these current studies, we have also found that ephrin-A5 treatment of A431 cells and over-expression of EphA2 in HEK293T cells can inhibit EGF-induced $\beta$-catenin phosphorylation (data unpublished). This implies that the Eph family regulates adherens junction stability through $\beta$-catenin phosphorylation. Future studies exploring how this regulation occurs in the lens may clarify the role of the Eph family in lens development. 


\section{Summary and future directions}

The importance of the Eph family in lens biology is a new area of study that is growing quickly and providing a greater understanding of lens development and maintenance. The current studies have uncovered previously unknown roles of the SAM and kinase domains in the EphA2 receptor, as well as have established a relationship between the Eph family and the adherens junction. However, the precise functional roles this category of receptor tyrosine kinases plays in the lens remain to be fully elucidated.

Thus far, of the members of the Eph family, only the EphA2 receptor and ephrin-A5 ligand have been identified as critical players in lens development. The appearance of such a drastic phenotype is surprising given the high level of redundancy within the system. In addition, we have observed several other Eph family molecules are also expressed within the murine lens, and that this expression appears early in embryonic development (data unpublished). However, the cataracts in both the human patients and mouse models indicate that the major deformities occur in the postnatal lens. This early expression indicates that the Ephs may have developmental functions within the lens that are compensated for in early lens development but not in later stages. Understanding the role of the Eph family in early lens development may elucidate novel functions.

Analysis of EphA2 activity within the lens has indicated that the SAM and kinase domains play significant roles. The SAM domain mutations are of particular interest given the limited knowledge regarding the function of this domain in Eph receptors. However, given the unique nature of the lens fiber cells and EphA2 expression being observed predominantly within this cellular population, functional studies on the role of EphA2 in the lens may be potentially difficult. Transgenic knock-in mouse studies in which EphA2 is replaced with the various human EPHA2 mutations may prove particularly valuable in elucidating whether protein localization, activation, and/or levels are affected.

Downstream targets of EphA2 and ephrin-A5 also remain to be elucidated. The effects of these molecules on the adherens junction indicate the critical role the Ephs play in regulating intercellular interactions within the lens. These interactions in the mature lens are particular important in maintaining proper lens function. Understanding how the Ephs regulate these adhesion molecules to maintain the unique structure of the lens will provide further insights into lens biology.

1 Resnikoff S, Pascolini D, Mariotti S P, et al. Global magnitude of visual impairment caused by uncorrected refractive errors in 2004. Bull World Health Organ, 2008, 86: 63-70

2 Resnikoff S, Pascolini D, Etya'ale D, et al. Global data on visual impairment in the year 2002. Bull World Health Organ, 2004, 82: 844-851

3 Congdon N G, Friedman D S, Lietman T. Important causes of visual impairment in the world today. JAMA, 2003, 290: 2057-2060

4 Zhang Q, Guo X, Xiao X, et al. Clinical description and genome wide linkage study of $\mathrm{Y}$-sutural cataract and myopia in a Chinese family. Mol Vis, 2004, 10: 890-900

5 Santana A, Waiswol M, Arcieri E S, et al. Mutation analysis of CRYAA, CRYGC, and CRYGD associated with autosomal dominant congenital cataract in Brazilian families. Mol Vis, 2009, 15: 793-800

6 Lovicu F J, McAvoy J W. Growth factor regulation of lens development. Dev Biol, 2005, 280: 1-14

7 Danysh B P, Duncan M K. The lens capsule. Exp Eye Res, 2009, 88: 151-164

8 Shestopalov V I, Bassnett S. Three-dimensional organization of primary lens fiber cells. Invest Ophthalmol Vis Sci, 2000, 41: 859-863

9 Kuszak J R, Zoltoski R K, Tiedemann C E. Development of lens sutures. Int J Dev Biol, 2004, 48: 889-902

10 Wride M A. Lens fibre cell differentiation and organelle loss: many paths lead to clarity. Philos Trans R Soc Lond B Biol Sci, 2011, 366: 1219-1233

11 Dahm R. Lens fibre cell differentiation-A link with apoptosis? Ophthalmic Res, 1999, 31: 163-183

12 Bassnett S, Mataic D. Chromatin degradation in differentiating fiber cells of the eye lens. J Cell Biol, 1997, 137: 37-49

13 Sharma K K, Santhoshkumar P. Lens aging: effects of crystallins. Biochim Biophys Acta, 2009, 1790: 1095-1108

14 Bloemendal H, de Jong W, Jaenicke R, et al. Ageing and vision: structure, stability and function of lens crystallins. Prog Biophys Mol Biol, 2004, 86: 407-485

15 Horwitz J. Alpha-crystallin can function as a molecular chaperone. Proc Natl Acad Sci USA, 1992, 89: 10449-10453

16 Horwitz J, Emmons T, Takemoto L. The ability of lens alpha crystallin to protect against heat-induced aggregation is agedependent. Curr Eye Res, 1992, 11: 817-822

17 Rao P V, Huang Q L, Horwitz J, et al. Evidence that alpha-crystallin prevents non-specific protein aggregation in the intact eye lens. Biochim Biophys Acta, 1995, 1245: 439-447

18 Graw J. Genetics of crystallins: cataract and beyond. Exp Eye Res, 2009, 88: 173-189

19 Zhu M, Madigan M C, van Driel D, et al. The human hyaloid system: cell death and vascular regression. Exp Eye Res, 2000, 70: 767-776

20 Ito M, Yoshioka M. Regression of the hyaloid vessels and pupillary membrane of the mouse. Anat Embryol (Berl), 1999, 200: 403-411

21 Mathias R T, White T W, Gong X. Lens gap junctions in growth, differentiation, and homeostasis. Physiol Rev, 2010, 90: 179-206

22 Beyer E C, Kistler J, Paul D L, et al. Antisera directed against connexin43 peptides react with a $43-\mathrm{kD}$ protein localized to gap junctions in myocardium and other tissues. J Cell Biol, 1989, 108: 595-605

23 Gong X, Li E, Klier G, et al. Disruption of alpha3 connexin gene leads to proteolysis and cataractogenesis in mice. Cell, 1997, 91: 833-843

24 Paul D L, Ebihara L, Takemoto L J, et al. Connexin46, a novel lens gap junction protein, induces voltage-gated currents in nonjunctional plasma membrane of Xenopus oocytes. J Cell Biol, 1991, 115: 1077- 089

25 Nielsen P A, Baruch A, Shestopalov V I, et al. Lens connexins alpha3Cx46 and alpha8Cx50 interact with zonula occludens protein1 (ZO-1). Mol Biol Cell, 2003, 14: 2470-2481

26 Nielsen P A, Baruch A, Giepmans B N, et al. Characterization of the association of connexins and ZO-1 in the lens. Cell Commun Adhes, 2001, 8: 213-217

27 Rhett J M, Jourdan J, Gourdie R G. Connexin 43 connexon to gap junction transition is regulated by zonula occludens-1. Mol Biol Cell, 2011, 22: 1516-1528

28 Chai Z, Goodenough D A, Paul D L. Cx50 requires an intact PDZ binding motif and ZO-1 for the formation of functional intercellular channels. Mol Biol Cell, 2011, 22: 1516-1528 
29 Gong X, Baldo G J, Kumar N M, et al. Gap junctional coupling in lenses lacking alpha3 connexin. Proc Natl Acad Sci USA, 1998, 95: 15303-15308

30 Baldo G J, Gong X, Martinez-Wittinghan F J, et al. Gap junctional coupling in lenses from alpha(8) connexin knockout mice. J Gen Physiol, 2001, 118: 447-456

31 Rong P, Wang X, Niesman I, et al. Disruption of Gja8 (alpha8 connexin) in mice leads to microphthalmia associated with retardation of lens growth and lens fiber maturation. Development, 2002, 129: 167-174

32 White T W, Goodenough D A, Paul D L. Targeted ablation of connexin50 in mice results in microphthalmia and zonular pulverulent cataracts. J Cell Biol, 1998, 143: 815-825

33 Hamann S, Zeuthen T, La Cour M, et al. Aquaporins in complex tissues: distribution of aquaporins 1-5 in human and rat eye. Am J Physiol, 1998, 274: C1332-1345

34 Patil R V, Saito I, Yang X, et al. Expression of aquaporins in the rat ocular tissue. Exp Eye Res, 1997, 64: 203-209

35 Zampighi G A, Hall J E, Ehring G R, et al. The structural organization and protein composition of lens fiber junctions. J Cell Biol, 1989, 108: 2255-2275

36 Fitzgerald P G, Bok D, Horwitz J. Immunocytochemical localization of the main intrinsic polypeptide (MIP) in ultrathin frozen sections of rat lens. J Cell Biol, 1983, 97: 1491-1499

37 Gumbiner B M. Regulation of cadherin-mediated adhesion in morphogenesis. Nat Rev Mol Cell Biol, 2005, 6: 622-634

38 Takeichi M. Morphogenetic roles of classic cadherins. Curr Opin Cell Biol, 1995, 7: 619-627

39 Weis W I, Nelson W J. Re-solving the cadherin-catenin-actin conundrum. J Biol Chem, 2006, 281: 35593-35597

40 Nagafuchi A, Takeichi M. Transmembrane control of cadherinmediated cell adhesion: a $94 \mathrm{kDa}$ protein functionally associated with a specific region of the cytoplasmic domain of E-cadherin. Cell Regul, 1989, 1: 37-44

41 Nagafuchi A, Takeichi M. Cell binding function of E-cadherin is regulated by the cytoplasmic domain. EMBO J, 1988, 7: 36793684

42 Thoreson M A, Anastasiadis P Z, Daniel J M, et al. Selective uncoupling of p120(ctn) from E-cadherin disrupts strong adhesion. J Cell Biol, 2000, 148: 189-202

43 Yap A S, Niessen C M, Gumbiner B M. The juxtamembrane region of the cadherin cytoplasmic tail supports lateral clustering, adhesive strengthening, and interaction with p120ctn. J Cell Biol, 1998, 141: 779-789

44 Kinch M S, Clark G J, Der C J, et al. Tyrosine phosphorylation regulates the adhesions of ras-transformed breast epithelia. J Cell Biol, 1995, 130: 461-471

45 Miravet S, Piedra J, Castano J, et al. Tyrosine phosphorylation of plakoglobin causes contrary effects on its association with desmosomes and adherens junction components and modulates betacatenin-mediated transcription. Mol Cell Biol, 2003, 23: 7391-7402

46 Leonard M, Chan Y, Menko A S. Identification of a novel intermediate filament-linked $\mathrm{N}$-cadherin/gamma-catenin complex involved in the establishment of the cytoarchitecture of differentiated lens fiber cells. Dev Biol, 2008, 319: 298-308

47 Leonard M, Zhang L, Zhai N, et al. Modulation of N-cadherin junctions and their role as epicenters of differentiation-specific actin regulation in the developing lens. Dev Biol, 2011, 349: 363-377

48 Pontoriero G F, Smith A N, Miller L A, et al. Co-operative roles for E-cadherin and N-cadherin during lens vesicle separation and lens epithelial cell survival. Dev Biol, 2009, 326: 403-417

49 Ferreira-Cornwell M C, Veneziale R W, Grunwald G B, et al. $\mathrm{N}$-cadherin function is required for differentiation-dependent cytoskeletal reorganization in lens cells in vitro. Exp Cell Res, 2000, 256: $237-247$

50 Jun G, Guo H, Klein B E, et al. EPHA2 is associated with age-related cortical cataract in mice and humans. PLoS Genet, 2009, 5: e1000584

51 Kaul H, Riazuddin S A, Shahid M, et al. Autosomal recessive congenital cataract linked to EPHA2 in a consanguineous Pakistani family. Mol Vis, 2010, 16: 511-517

52 Tan W, Hou S, Jiang Z, et al. Association of EPHA2 polymorphisms and age-related cortical cataract in a Han Chinese population. Mol Vis, 2011, 17: 1553-1558

53 Zhang T, Hua R, Xiao W, et al. Mutations of the EPHA2 receptor tyrosine kinase gene cause autosomal dominant congenital cataract. Hum Mutat, 2009, 30: E603-611

54 Sundaresan P, Ravindran R D, Vashist P, et al. EPHA2 Polymorphisms and Age-Related Cataract in India. PLoS One, 2012, 7: e33001

55 Shiels A, Bennett T M, Knopf H L, et al. The EPHA2 gene is associated with cataracts linked to chromosome 1p. Mol Vis, 2008, 14: 2042-2055

56 Schlessinger J. Cell signaling by receptor tyrosine kinases. Cell, 2000, 103: 211-225

57 Robinson D R, Wu Y M, Lin S F. The protein tyrosine kinase family of the human genome. Oncogene, 2000, 19: 5548-5557

58 Hirai H, Maru Y, Hagiwara K, et al. A novel putative tyrosine kinase receptor encoded by the eph gene. Science, 1987, 238: 1717-1720

59 Pasquale E B. Eph receptor signalling casts a wide net on cell behaviour. Nat Rev Mol Cell Biol, 2005, 6: 462-475

60 Klein R. Bidirectional modulation of synaptic functions by Eph/ephrin signaling. Nat Neurosci, 2009, 12: 15-20

61 Himanen J P, Chumley M J, Lackmann M, et al. Repelling class discrimination: ephrin-A5 binds to and activates EphB2 receptor signaling. Nat Neurosci, 2004, 7: 501-509

62 Grunwald I C, Korte M, Adelmann G, et al. Hippocampal plasticity requires postsynaptic ephrinBs. Nat Neurosci, 2004, 7: 33-40

63 Mellitzer G, Xu Q, Wilkinson D G. Eph receptors and ephrins restrict cell intermingling and communication. Nature, 1999, 400: $77-81$

64 Yokoyama N, Romero M I, Cowan C A, et al. Forward signaling mediated by ephrin-B3 prevents contralateral corticospinal axons from recrossing the spinal cord midline. Neuron, 2001, 29: 85-97

65 Kullander K, Klein R. Mechanisms and functions of Eph and ephrin signalling. Nat Rev Mol Cell Biol, 2002, 3: 475-486

66 Qiao F, Bowie J U. The many faces of SAM. Sci STKE, 2005, 2005: re7

67 Stapleton D, Balan I, Pawson T, et al. The crystal structure of an Eph receptor SAM domain reveals a mechanism for modular dimerization. Nat Struct Biol, 1999, 6: 44-49

68 Thanos C D, Faham S, Goodwill K E, et al. Monomeric structure of the human EphB2 sterile alpha motif domain. J Biol Chem, 1999, 274: 37301-37306

69 Thanos C D, Goodwill K E, Bowie J U. Oligomeric structure of the human EphB2 receptor SAM domain. Science, 1999, 283: 833-836

70 Dufour A, Egea J, Kullander K, et al. Genetic analysis of EphA-dependent signaling mechanisms controlling topographic mapping in vivo. Development, 2006, 133: 4415-4420

71 Kullander K, Mather N K, Diella F, et al. Kinase-dependent and kinase-independent functions of EphA4 receptors in major axon tract formation in vivo. Neuron, 2001, 29: 73-84

72 Park E K, Warner N, Bong Y S, et al. Ectopic EphA4 receptor induces posterior protrusions via FGF signaling in Xenopus embryos. Mol Biol Cell, 2004, 15: 1647-1655

73 Himanen J P, Rajashankar K R, Lackmann M, et al. Crystal structure of an Eph receptor-ephrin complex. Nature, 2001, 414: 933-938

74 Toth J, Cutforth T, Gelinas A D, et al. Crystal structure of an ephrin ectodomain. Dev Cell, 2001, 1: 83-92

75 Smith F M, Vearing C, Lackmann M, et al. Dissecting the EphA3/Ephrin-A5 interactions using a novel functional mutagenesis screen. J Biol Chem, 2004, 279: 9522-9531

76 Hattori M, Osterfield M, Flanagan J G. Regulated cleavage of a contact-mediated axon repellent. Science, 2000, 289: 1360-1365

77 Wykosky J, Palma E, Gibo D M, et al. Soluble monomeric EphrinA1 is released from tumor cells and is a functional ligand for 
the EphA2 receptor. Oncogene, 2008, 27: 7260-7273

78 Alford S, Watson-Hurthig A, Scott N, et al. Soluble ephrin a1 is necessary for the growth of HeLa and SK-BR3 cells. Cancer Cell Int, 2010, 10: 41

79 Pasquale E B. Eph-ephrin bidirectional signaling in physiology and disease. Cell, 2008, 133: 38-52

80 Pasquale E B. Eph receptors and ephrins in cancer: bidirectional signalling and beyond. Nat Rev Cancer, 2010, 10: 165-180

81 Eiberg H, Lund A M, Warburg M, et al. Assignment of congenital cataract Volkmann type (CCV) to chromosome 1p36. Hum Genet, 1995, 96: 33-38

82 Ionides A C, Berry V, Mackay D S, et al. A locus for autosomal dominant posterior polar cataract on chromosome 1p. Hum Mol Genet, 1997, 6: 47-51

83 Burdon K P, Hattersley K, Lachke S A, et al. Investigation of eight candidate genes on chromosome $1 \mathrm{p} 36$ for autosomal dominant total congenital cataract. Mol Vis, 2008, 14: 1799-1804

84 Hattersley K, Laurie K J, Liebelt J E, et al. A novel syndrome of paediatric cataract, dysmorphism, ectodermal features, and developmental delay in Australian Aboriginal family maps to 1p35.3-p36.32. BMC Med Genet, 2010, 11: 165

85 Mitchell K J, Pinson K I, Kelly O G, et al. Functional analysis of secreted and transmembrane proteins critical to mouse development. Nat Genet, 2001, 28: 241-249

86 Oya-Ito T, Liu B F, Nagaraj R H. Effect of methylglyoxal modification and phosphorylation on the chaperone and antiapoptotic properties of heat shock protein 27. J Cell Biochem, 2006, 99: 279-291

87 Arrigo A P, Simon S, Gibert B, et al. Hsp27 (HspB1) and alphaB-crystallin (HspB5) as therapeutic targets. FEBS Lett, 2007, 581: 3665-3674

88 Jakob U, Gaestel M, Engel K, et al. Small heat shock proteins are molecular chaperones. J Biol Chem, 1993, 268: 1517-1520

89 Shi Y, De Maria A, Bennett T, et al. A role for epha2 in cell migration and refractive organization of the ocular lens. Invest Ophthalmol Vis Sci, 2012, 53: 551-559

90 Park J E, Son A I, Hua R, et al. Human Cataract Mutations in EPHA2 SAM Domain Alter Receptor Stability and Function. PLoS ONE, 2012, in press

91 Kaplan N, Fatima A, Peng H, et al. EphA2/Ephrin-A1 signaling complexes restrict corneal epithelial cell migration. Invest Ophthalmol Vis Sci, 2012, 53: 936-945
92 Cooper M A, Son A I, Komlos D, et al. Loss of ephrin-A5 function disrupts lens fiber cell packing and leads to cataract. Proc Natl Acad Sci U S A, 2008, 105: 16620-16625

93 Cheng C, Gong X. Diverse Roles of Eph/ephrin Signaling in the Mouse Lens. PLoS One, 2011, 6: e28147

94 Sandilands A, Wang X, Hutcheson A M, et al. Bfsp2 mutation found in mouse 129 strains causes the loss of CP49 and induces vimentin-dependent changes in the lens fibre cell cytoskeleton. Exp Eye Res, 2004, 78: 109-123

95 Alizadeh A, Clark J, Seeberger T, et al. Characterization of a mutation in the lens-specific CP49 in the 129 strain of mouse. Invest Ophthalmol Vis Sci, 2004, 45: 884-891

96 Feldheim D A, Kim Y I, Bergemann A D, et al. Genetic analysis of ephrin-A2 and ephrin-A5 shows their requirement in multiple aspects of retinocollicular mapping. Neuron, 2000, 25: 563-574

97 Kikawa K D, Vidale D R, Van Etten R L, et al. Regulation of the EphA2 kinase by the low molecular weight tyrosine phosphatase induces transformation. J Biol Chem, 2002, 277: 39274-39279

98 Parri M, Buricchi F, Taddei M L, et al. EphrinA1 repulsive response is regulated by an EphA2 tyrosine phosphatase. J Biol Chem, 2005, 280: 34008-34018

99 Fang W B, Ireton R C, Zhuang G, et al. Overexpression of EPHA2 receptor destabilizes adherens junctions via a RhoA-dependent mechanism. J Cell Sci, 2008, 121: 358-368

100 Nowakowski J, Cronin C N, McRee D E, et al. Structures of the cancer-related Aurora-A, FAK, and EphA2 protein kinases from nanovolume crystallography. Structure, 2002, 10: 1659-1667

101 Miura K, Nam J M, Kojima C, et al. EphA2 engages Git1 to suppress Arf6 activity modulating epithelial cell-cell contacts. Mol Biol Cell, 2009, 20: 1949-1959

102 Solanas G, Cortina C, Sevillano M, et al. Cleavage of E-cadherin by ADAM10 mediates epithelial cell sorting downstream of EphB signalling. Nat Cell Biol, 2011, 13: 1100-1107

103 Orsulic S and Kemler R. Expression of Eph receptors and ephrins is differentially regulated by E-cadherin. J Cell Sci, 2000, 113: 17931802

104 Zantek N D, Azimi M, Fedor-Chaiken M, et al. E-cadherin regulates the function of the EphA2 receptor tyrosine kinase. Cell Growth Differ, 1999, 10: 629-638

105 Kasemeier-Kulesa J C, Bradley R, Pasquale E B, et al. Eph/ephrins and $\mathrm{N}$-cadherin coordinate to control the pattern of sympathetic ganglia. Development, 2006, 133: 4839-4847

Open Access This article is distributed under the terms of the Creative Commons Attribution License which permits any use, distribution, and reproduction in any medium, provided the original author(s) and source are credited. 


\section{SCIENCE CHINA \\ Life Sciences}

May 2012 Vol.55 No.5

doi: $10.1007 / \mathrm{s} 11427-012-4318-7$

\section{Biographical Sketch}

Dr. Zhou RenPing is a Professor and the Chairman of the Department of Chemical Biology at Ernest Mario School of Pharmacy, Rutgers University. Dr. Zhou grew up in a village in Yizheng, Jiangsu Province, China, and earned his bachelor's degree in biology from Nanjing Normal University. He was a CUSBEA fellow of Class II (1983). Dr. Zhou obtained his Ph.D. in molecular biology in University of California at Berkeley in 1989, and performed postdoctoral training at National Cancer Institute, Fredrick, Maryland. In 1993, Dr. Zhou was appointed Assistant Professor at Rutgers University, promoted to Associate Professor in 1998, and full Professor in 2004. He was appointed Chairman of Chemical Biology in 2010. Dr. Zhou's laboratory has been interested in how molecular signals regulate development of various tissues and organs. His major contributions include the elucidation of repulsive axon guidance molecules in the wiring of neural circuits, and the discovery of the involvement of Eph/ephrin family molecules in cataract development. Dr. Zhou teaches both pharmacy and graduate students signal transduction mechanisms in "Advanced Cell Biology" and "Microbiology". Dr. Zhou has received several research awards including Johnson \& Johnson Discovery Award and Michael J. Fox Parkinson's Research Award.

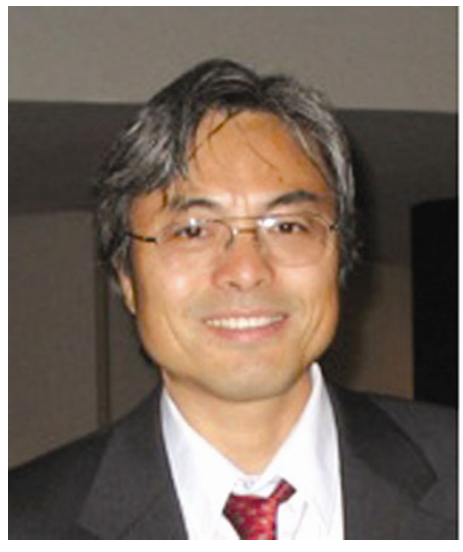

